\title{
Aicardi's Diseases of the Nervous System in Childhood: Alexis Arzimanoglou, University Hospitals of Lyon, France with Anne O'Hare, Michael V Johnston, Robert Ouvrier (eds)
}

\author{
Published by Mac Keith Press, London; 2018; Fourth Edition; \\ ISBN: 978-1-909962-80-4; Pages: 1496; Price: $£ 199.95$
}

Veronica Arora $^{1} \cdot$ Ishwar Verma ${ }^{1}$

Received: 12 July 2019 / Accepted: 12 July 2019 /Published online: 22 August 2019

(C) Dr. K C Chaudhuri Foundation 2019

This book is a combined effort of 47 leading pediatric neurologists from all over the world. It covers systematically the whole range of pediatric neurological disorders. Each chapter is written by authors who have made substantial contribution to the topic. It has been carefully divided into sections and chapters starting from the basics of embryology, fetal brain anomalies, developmental disorders followed by other pediatric disorders. There are 12 parts divided into chapters over a total of 1500 pages.

An attractive part of the book is the large number of pictures and illustrations which makes it delightful for the eyes. The EEG's and the MRI images are appropriate and show the characteristic features. The language is simple and clear. Particularly interesting and well covered areas of the book are the genetic disorders, which will give a pediatric neurologist an excellent review of these less spoken of disorders. It gives a quick review of developments in this area. Another striking section is the one on metabolic disorders of the central nervous system. All important concepts of metabolic disease are covered, though briefly.

There is an excellent chapter on fetal neurology, covering embryology and various malformations. Perinatal period has been well described, especially the part on hypoxic ischemic encephalopathy. Epilepsy has been exhaustively described.

This updated version is definitely a gem of a book and should be on the shelves of libraries of departments of pediatrics, neurology and clinical genetics. We are convinced that this book will be readily adopted by most students and pediatricians and that it is here to stay. We would recommend that in future the book be published in two volumes to enhance easy handling.

Publisher's Note Springer Nature remains neutral with regard to jurisdictional claims in published maps and institutional affiliations.
Ishwar Verma

icverma@gmail.com

1 Department of Genetics and Genomics, Sir Ganga Ram Hospital, New Delhi 110060, India 